TP Periodica Polytechnica Electrical Engineering and Computer Science

60(4), pp. 261-265, 2016

DOI: $10.3311 /$ PPee. 10019

Creative Commons Attribution (i)

\section{Optimal Charging/Discharging of PHEVs for Predictability Enhancement of Wind Power Generation}

\author{
Ali Abdelfatah ${ }^{1,2^{*}}$, Dávid Raisz ${ }^{2}$
}

Received 10 June 2016; accepted 23 August 2016

\begin{abstract}
In a context of rapidly expanding renewable energy resources, the wind power is the most interest. Because of intermittent nature of wind turbines, it is difficult to predict and control the wind power generation. At high penetration level, an extra fast response reserve capacity is needed to compensate the shortage of generation when a sudden variation of wind takes place. In order to manage this uncertainty, to minimize the system losses, and to improve the voltage profiles, the injected power to the grid should be kept at its optimal level throughout the day. This paper presents an approach to keep the injected power at its optimal level by combining the wind power generation system with Plug-in Hybrid Electric Vehicles (PHEVS) and optimal utilizing of vehicle-to-grid (V2G) capacities. Optimal PHEVs charging/discharging can stabilize the injected power of the wind turbines by storing electric energy during high wind speed and deliver it during low wind speed. So, it is important to estimate enough number of participating PHEVS for the desired applications. The proposed approach is tested using a 33-bus distribution system with a variety of case studies and actual wind speed.
\end{abstract}

\section{Keywords}

Plug-in Hybrid Electric Vehicle (PHEVs), vehicle-to-grid $(V 2 G)$, wind power generation, distribution system, power loss

\footnotetext{
${ }^{1}$ Department of Electrical Engineering, Faculty of Engineering,

South Valley University, 83523 Qena, Egypt

${ }^{2}$ Department of Electric Power Engineering, Faculty of Electrical Engineering and Informatics, Budapest University of Technology and Economics, 1111 Budapest, Hungary

*Corresponding author, e-mail: engaaa2010@gmail.com
}

\section{Introduction}

The demand for electric energy has been increasing rapidly all over the world. This imposed a significant burden on the existing energy resources and led to an increase in environmental pollution and global warming. Using of renewable energy resources, which are clean and unlimited sources of energy, is an important solution for these problems [1]. Wind and solar energy are the most popular renewable energy resources. These resources are used as distributed generation (DGs) units technology to be defined as newer sources of power.

Wind energy is considered one of electricity sources, which is growing rapidly, and, of course, one of the fastest growing markets in the world [2]. Wind energy is present technical challenges because of its nature of intermittent. Therefore, it is difficult to predict the wind power generation and subject to factors outside the control of the operating company, which can make matching electricity supply to consumer demand problematic. Controlling of wind power generation and its potential effects on the electrical grid are different from traditional energy sources. At high penetration levels, an extra fast response reserve capacity is needed to cover the shortfall of a generation when a sudden deficit of wind takes place [3].

In recent years, many technical and financial methods have been suggested to solve the problem of uncertainty of wind power and to make wind power more reliable. In [4], battery storage are used to mitigate wind power fluctuations, and superconducting magnetic energy storage (SMES) is used in [5]. One method to mitigate the power and voltage fluctuation is to use PHEVs batteries. As PHEVs are still connected to the grid, they can charge/discharge to compensate any shortage/raise in the active power in a distribution system [6]. This concept of utilizing the PHEVs to support the grid is termed as a vehicleto-grid (V2G) [7, 8].

PHEVs have the potential to provide numerous ancillary services to the grid owing to the fact that they can act as either loads or sources when connected to the grid. In other words, PHEVs can be assumed as controllable loads to levelize the system demand during the off-peak period and as generation devices during peak period or high electricity price period to 
provide capacity and energy services to grid $[9,10]$. Unlike large generators, PHEVs batteries energy storage and power electronics are designed to provide large and frequent power fluctuations over short time period [11]. This makes the PHEVs especially more suitable for regulation. Once the vehicle receives a signal from the aggregator, it can respond in less than a second to change its power output.

The battery of a PHEV is a very limited resource of energy that its impact on the grid can be neglected. The suggested method is based on the use of V2G aggregator for accommodating the electrical energy of PHEVs in order to access high storage capacity from small battery capacity of PHEVs that can affect the grid usefully. Due to the population of PHEVs, many papers discussed the role of the $\mathrm{V} 2 \mathrm{G}$ aggregator in managing and controlling PHEVs [7, 8, 12-15]. The main role of V2G aggregator is to collect the PHEVs into one existence that can act as a generation or storage, which capable of supplying the energy needed by the grid or as a controllable load to be charged in a method to keep the system reliability. Moreover, the V2G aggregator determines which PHEV has to be selected to join the aggregation.

In this paper, an approach to manage the wind power by using high penetration of PHEVs is proposed. The proposed approach presents an optimal charging/discharging of PHEVs based on a multi-objective function including active power losses and voltage deviations to keep the injected power to the grid at its optimal level. Therefore, the power losses, fluctuation of wind power, and voltage deviations are decreased. This concept makes the wind power a more reliable capacity. According to the wind speed variation, the V2G aggregator will decide to use a specific number of participation PHEVs, so the number of PHEVs will be changed every day depending on the wind speed of that day.

The rest of this paper is organized as follows. The objective function, limitations, and PHEVs battery model are presented in Section 2. Sections 3 discuss the proposed solution process. Simulation results are discussed in Section 4, and conclusions are included in Section 5.

\section{Problem Formulation}

\subsection{Objective Function}

In this study, the main objectives are as below:

- Minimizing the active power loss in the grid at each time interval $t$.

- Minimizing the deviation of all bus voltages at each time interval $t$.

Thus, there are two objectives that should be considered to form the objective function. In the objective function, each objective has a weight coefficient, the value of which shows the relative importance of that objective compared to the other one. So, the objective function is defined as:

$$
\begin{gathered}
\text { Minimize } O F_{t}=K_{P L, t} P L_{t}+K_{V D, t} V D_{t} \\
K_{P L, t}+K_{V D, t}=1
\end{gathered}
$$

where $O F_{t}, K_{P L, t}, K_{V D, t}, P L_{t}$, and $V D_{t}$ are the objective function, weight coefficient related to active power loss, weight coefficient related to voltage profile deviation, active power losses, and voltage profile deviation at time interval $t$, respectively. The objective functions are described as follows:

$$
\begin{gathered}
P L_{t}=\sum_{\substack{k=1 \\
k=(i, j)}}^{N T L} G_{k}\left[V_{i, t}^{2}+V_{j, t}^{2}-2 V_{i, t} V_{j, t} \cos \delta_{i j, t}\right] \\
V D_{t}=\sum_{i=1}^{N B} \frac{\left(V_{i, t}-V_{N i}\right)^{2}}{V_{N i}^{2}}
\end{gathered}
$$

where NTL, NB, $V_{i, t}, V_{N i}, G_{k}$, and $\delta_{i j, t}$ are number of transmission lines, number of buses, voltage at ith bus, nominal voltage of $i$ th bus, conductance between two buses, and difference between voltage angles at buses $i, j$, respectively.

\section{Subject to:}

$$
\begin{aligned}
& P_{g_{i, t}}+P_{A g_{i, t}}-P_{D_{i, t}}-V_{i, t} \sum_{j=1}^{N B} V_{j, t} * \\
& {\left[G_{i j} \cos \left(\delta_{i, t}-\delta_{j, t}\right)+B_{i j} \sin \left(\delta_{i, t}-\delta_{j, t}\right)\right]=0} \\
& Q_{g_{i, t}}-Q_{D_{i, t}}-V_{i, t} \sum_{j=1}^{N B} V_{j, t} * \\
& {\left[G_{i j} \sin \left(\delta_{i, t}-\delta_{j, t}\right)+B_{i j} \cos \left(\delta_{i, t}-\delta_{j, t}\right)\right]=0} \\
& V_{1}=1.0 \quad \delta_{1}=0.0
\end{aligned}
$$

where $P_{g_{i, t}}, Q_{g_{i, t}}, P_{A g_{i, t}}, P_{D_{i, t}}, Q_{D_{i, t}}$ and $B_{i j}$ are (at each time interval $t$ ) the active power generated at bus $i$, reactive power generated at bus $i, \mathrm{~V} 2 \mathrm{G}$ aggregator power, active power demand at bus $i$, reactive power demand at bus $i$, and susceptance between bus $i$ and bus $j$, respectively.

$$
\begin{gathered}
V_{i}^{\min } \leq V_{i, t} \leq V_{i}^{\max } \\
P_{A g_{i}}^{\min } \leq P_{A g_{i, t}} \leq P_{A g_{i}}^{\max } \quad i=1,2, \ldots \ldots N_{A g}
\end{gathered}
$$

where $V_{i}^{\min }, V_{i}^{\max }, P_{A g_{i}}^{\min }$ and $P_{A g_{i}}^{\max }$ are the minimum voltage, maximum voltage, minimum $\mathrm{V} 2 \mathrm{G}$ aggregator power, and maximum $\mathrm{V} 2 \mathrm{G}$ aggregator power at bus $i$, respectively.

\subsection{Battery Model for PHEV}

For each time interval $(t)$, the state of charge (SOC) of the PHEV battery is updated according to the charging/discharging status as follows:

$$
S O C_{i, t}=S O C_{i, t-1}+P_{c h i, t} \cdot \Delta t \cdot X_{t}-P_{d c i, t} \cdot \Delta t \cdot Y_{t}
$$


where $S O C_{i, t}, P_{c h i, t}$, and $P_{d c i, t}$ are state of charge, charging rate, and discharging rate of ith $\mathrm{PHEV}$ at time interval $t$, respectively. $\mathrm{X}$ and $\mathrm{Y}$ are binary variables $(X, Y \in\{0,1\})$, where $\mathrm{X}$. $\mathrm{Y}=0$ because battery charging and discharging cannot be simultaneously performed.

The charging/discharging power of each PHEV battery at time interval $t$ is described as follows:

$$
\begin{gathered}
P_{c h i, t}=\frac{C_{i}-E_{i, t}}{\sum_{i=1}^{N} C_{i}-\sum_{i=1}^{N} E_{i, t}} \cdot P_{A g, t} \\
P_{d c i, t}=\frac{E_{i, t}}{\sum_{i=1}^{N} E_{i, t}} \cdot P_{A g, t}
\end{gathered}
$$

where $\mathrm{C}_{\mathrm{i}}, \mathrm{E}_{i, t}$ are the total capacity and stored energy of $i^{\text {th }}$ $\mathrm{PHEV}$, respectively.

\section{PHEV battery constraint}

i. Storage capacity constraint

$$
S O C_{i, \text { min }} \leq S O C_{i, t} \leq S O C_{i, \text { max }}
$$

ii. Rate of charge constraint

$$
P_{c h i, t} \leq P_{c h i}^{\max }
$$

iii. Rate of discharge constraint

$$
P_{d c i, t} \leq P_{d c i}^{\max }
$$

where $S O C_{i, \min }, S O C_{i, \max }, P_{c h i}^{\max }$, and $P_{d c i}^{\max }$ are minimum SOC, maximum SOC, maximum charging rate, and maximum discharging rate of $i^{\text {th }} \mathrm{PHEV}$, respectively.

\section{Solution Method}

The flowchart of the proposed approach is shown in Fig. 1. The figure shows that, firstly, the time interval is initialized. Secondly, the system data is read. Thirdly, the number of PHEVs is estimated and their batteries status are measured. Then, the optimization problem is solved to calculate the optimal V2G aggregator power, and after that the V2G aggregator power is checked according to the following:

- If it is positive (i.e. PHEVs are in charging mode), we calculate the charging rate for each PHEV using (11) (if it is greater than its maximum charging rate, it should be fixed at maximum charging rate).

- If it is negative (i.e. PHEVs are in discharging mode), we calculate the discharging rate for each PHEV using (12) (if it is greater than its maximum discharging rate, it should be fixed at the maximum discharging rate).

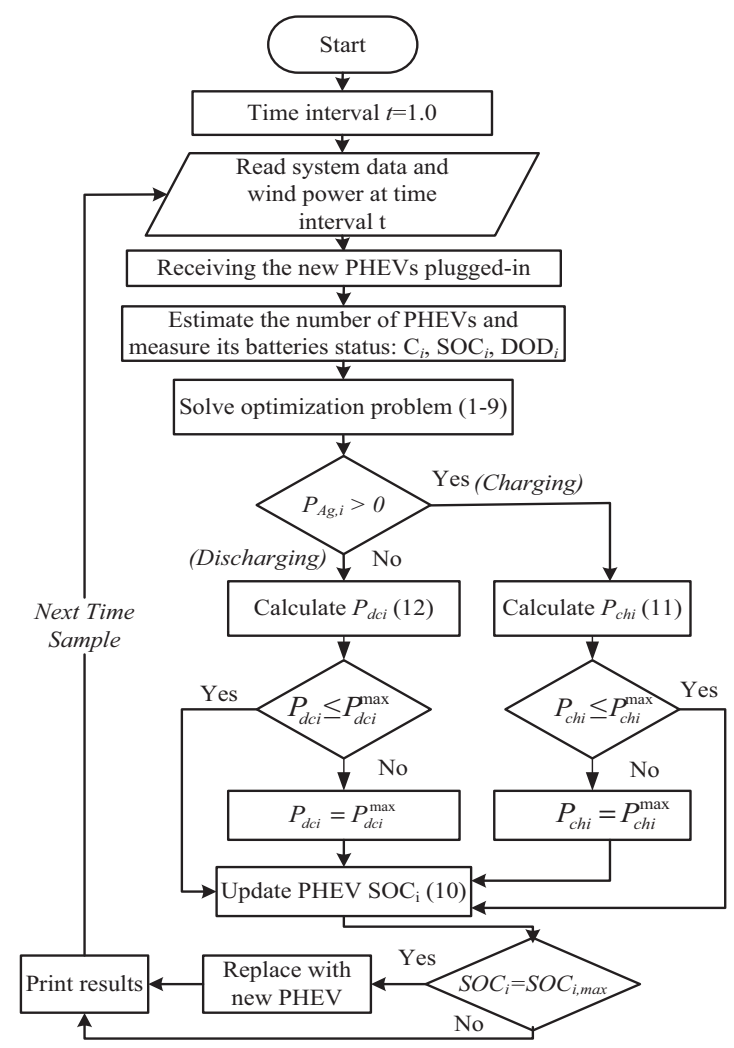

Fig. 1 Flow chart of proposed approach.

After calculating charging/discharging rate, the SOC of PHEVs is updated (10) and check if it is reached its maximum SOC or not. The PHEVs that reached their maximum SOC replaced by new units. Finely, the results are printed and the algorithm goes to the next time sample and repeats the above process.

\section{Results and discussions}

The 33-bus distribution system has been used to test the proposed method. This MV system comprises a single $12.66 \mathrm{kV}$ supply point, 33-buses, 3 laterals, and 32 branches. The total active and reactive loads are 3.715 MW and 2.3 Mvar, respectively, with real power loss at nominal loading of $0.203 \mathrm{~kW}$. The complete system data are given in [16].

The daily wind power generation used in this study is shown in Fig. 2. It is connected to bus 6, where it is in the central of the loads. Also, V2G aggregator is connected to the same bus to enhance the wind power generation. Five models of PHEVs are considered in this paper. The main characteristics of these models (e.g. battery energy storage capacity, the initial state of charge (SOC), Depth of Discharge (DOD)) are summarized in Table 1. Number of PHEVs have been determined by the aggregator in that day are assumed 750 (i.e. 150 PHEVs for each model). The maximum charging/discharging rates have been chosen $4 \mathrm{~kW}$ [17]. The lower and upper voltage thresholds should be 0.95 p.u. and 1.05 p.u., respectively. The values of the two weight coefficients have been chosen as $K_{P L, t}=0.45$ and $K_{V D, t}=0.55$. The real time scenarios are modeled using daily load profiles shown in 
Fig. 3. The optimization problem described in Section 2 is solved by using the student version of the AMPL solver [18].

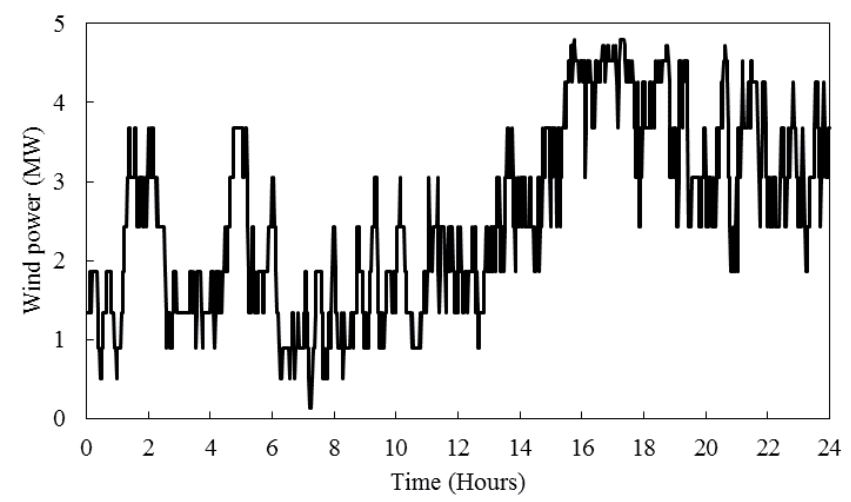

Fig. 2 Daily wind power generation.

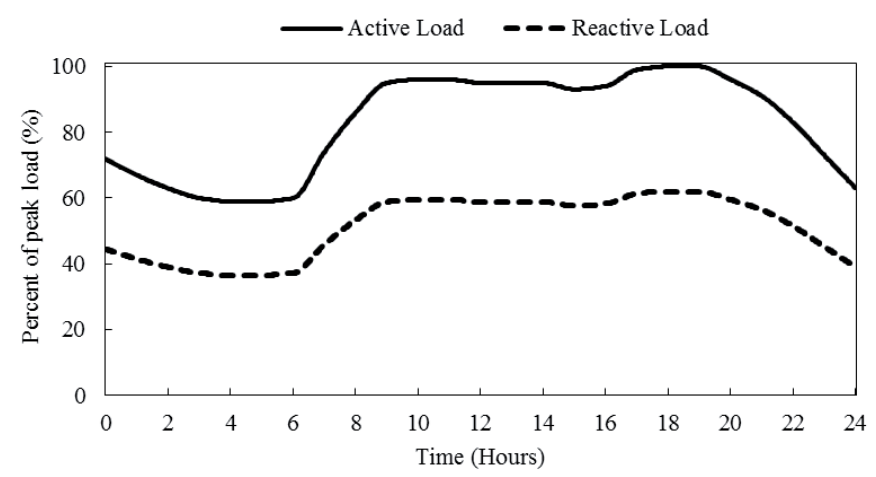

Fig. 3 Daily load profile.

Table 1 PHEV Models

\begin{tabular}{llll}
\hline Model & $\begin{array}{l}\text { Battery capacity } \\
\text { kWh }\end{array}$ & $\begin{array}{l}\text { Initial } \\
\text { SOC \% }\end{array}$ & $\begin{array}{l}\text { Maximum } \\
\text { DOD \% }\end{array}$ \\
\hline Model 1 & 27.4 & 30 & 80 \\
Model 2 & 5.33 & 70 & 60 \\
Model 3 & 16 & 40 & 65 \\
Model 4 & 24 & 50 & 65 \\
Model 5 & 16 & 60 & 65 \\
\hline
\end{tabular}

In order to verify the positive role of the developed approach in enhancing system performance, three different cases are studied, as follows:

Case 1: This base case is performed with no wind turbines or PHEVs are connected.

Case 2: Only wind turbines are connected, no PHEVs.

Case 3: Both wind turbines and PHEVs are connected.

Case 1 represents the reference case while case 2 shows the effect of wind power generation on the grid. The proposed approach (case 3 ) shows the advantage of optimal utilizing the V2G capacities in predictability enhancement of wind power generation and improving the system performance.
Voltage profile at bus 18 are shown in Fig. 4 for three cases. Voltage profiles at other buses are not illustrated because they have better profiles than bus 18 . The total system losses are compared for the three cases in Fig. 5. The variation of the OF for the three cases is illustrated in Fig. 6.

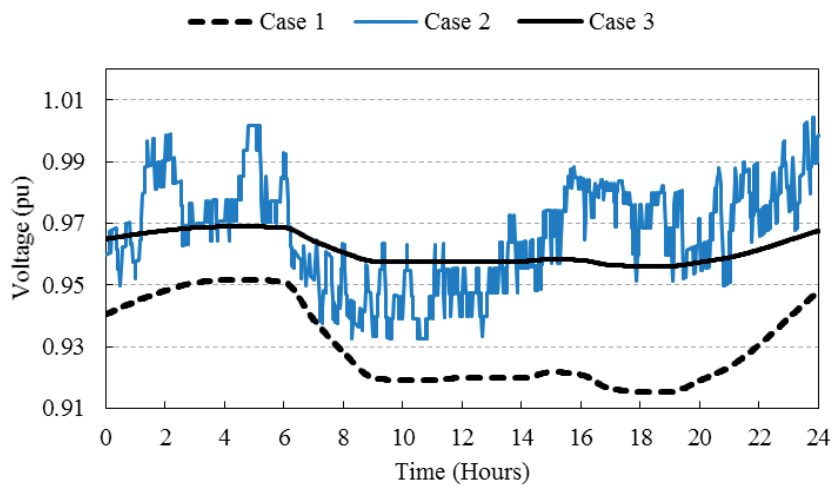

Fig. 4 Voltage profile at bus 18 .

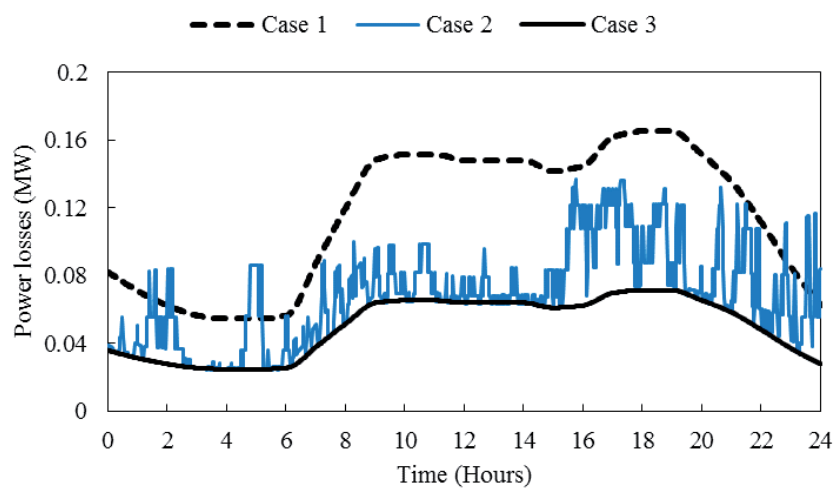

Fig. 5 Power losses.

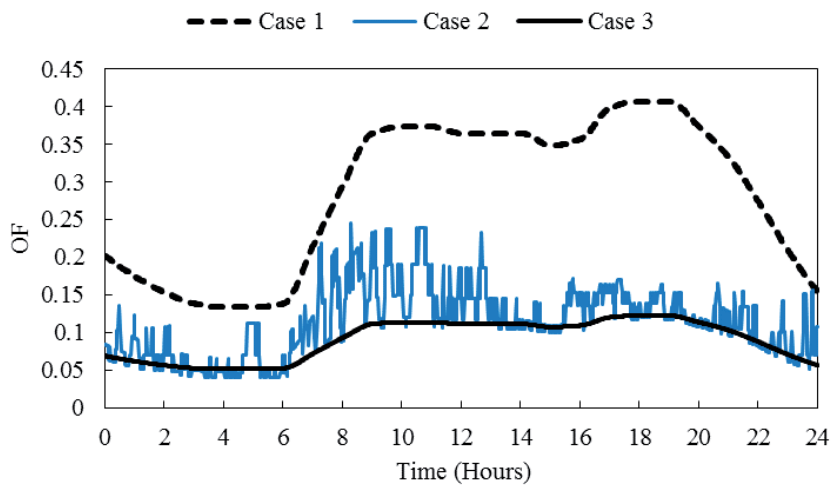

Fig. 6 Normalized objective function.

Figure 4 shows that the voltage profiles are greatly improved and kept between limits and the voltage fluctuation is completely enhanced,when combine the wind power generation with PHEVs at its optimal charging/discharging. Figure 5 shows that when we combine the wind power generation with PHEVs, the total system losses are highly decreased compared to other two cases. It is clear from Fig. 6 that OF in case 3 has lower values than cases 1 and 2 .

The wind power generation, V2G aggregator power, and injected power to the grid are shown in Fig. 7. It is seen from 
Fig. 7 that optimal V2G aggregator power completely enhance the wind power fluctuations by charging at high generation (positive part of $\mathrm{V} 2 \mathrm{G}$ aggregator power) and discharging at low generation (negative part of V2G aggregator power), and keep the injected power to grid smooth and at its optimal value throughout the day. The changing of SOC for different PHEVs models due to charging/ discharging is illustrated in Fig. 8.

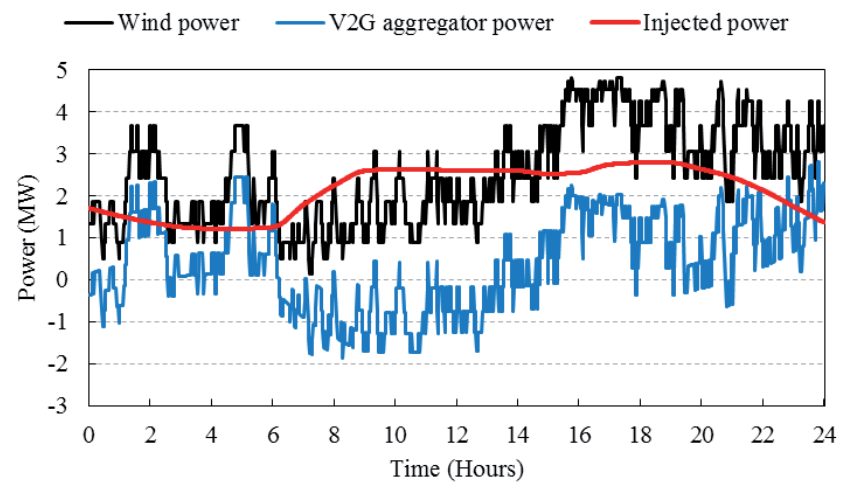

Fig. 7 Wind, V2G aggregator, and injected power.

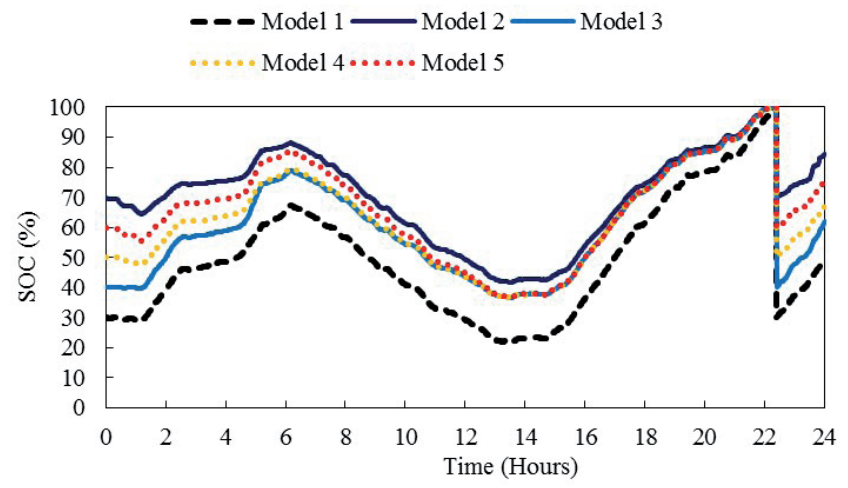

Fig. 8 SOC for different PHEVs Models.

\section{Conclusions}

This paper proposed an approach to optimally utilize the V2G capacities of PHEVs and reduce the uncertainty of wind power. The proposed approach adopts multi-objective function with considering system constraints. The optimization problem is solved by using the student version of the AMPL solver. The effectiveness of the proposed approach is demonstrated through simulating daily operation of the 33-bus distribution system. Simulation results demonstrate the efficiency of the proposed algorithm to enhance the utilization and predictability of wind power. The power losses are significantly reduced, and voltage profiles are greatly improved for the optimal charging/discharging scenario when compared to the cases with no V2G services.

\section{References}

[1] Jahdi, S., Lai, L. L., Nankoo, D. "Grid integration of wind-solar hybrid renewables using AC/DC converters as DG power sources." In: 2011 World Congress on Sustainable Technologies (WCST). London, 2011, pp. 171-177.

[2] Singh, S. N., Erlich, I. "Strategies for Wind Power Trading in Competitive Electricity Markets." IEEE Transactions on Energy Conversion. 23(1), pp. 249-256. 2008. DOI: 10.1109/TEC.2007.914179
[3] Khalid, M., Savkin, A. V. "An optimal operation of wind energy storage system for frequency control based on model predictive control." Renewable Energy. 48(C), pp. 127-132. 2012. DOI: 10.1016/j.renene.2012.03.038

[4] Ganti, V. C., Singh, B., Aggarwal, S. K., Kandpal, T. C. "DFIG-Based Wind Power Conversion with Grid Power Leveling for Reduced Gusts." IEEE Transactions on Sustainable Energy. 3(1), pp. 12-20. 2012.

DOI: 10.1109/TSTE.2011.2170862

[5] Kinjo, T., Sennjyu, T., Urasaki, N., Fujita, H. "Terminal-voltage and output-power regulation of wind-turbine generator by series and parallel compensation using SMES." IEE Proceedings - Generation, Transmission and Distribution. 153(3), 276-282. 2006.

DOI: 10.1049/ip-gtd:20045189

[6] Ghanbarzadeh, T., Baboli, P. T., Rostami, M., Moghaddam, M. P., SheikhEl-Eslami, M. K. "Wind farm power management by high penetration of PHEV." In: 2011 IEEE Power and Energy Society General Meeting, San Diego, USA, July 24-29, 2011, pp. 1-5. DOI: 10.1109/PES.2011.6039902

[7] Tomić, J., Kempton, W. "Using fleets of electric-drive vehicles for grid support." Journal of Power Sources. 168(2), pp. 459-468. 2007.

DOI: 10.1016/j.jpowsour.2007.03.010

[8] Kempton, W., Tomić, J. "Vehicle-to-grid power implementation: From stabilizing the grid to supporting large- scale renewable energy." Journal of Power Sources. 144(1), pp. 280-294. 2005.

DOI: 10.1016/j.jpowsour.2004.12.022

[9] Kulshrestha, P., Wang, L., Chow, MY., Lukic, S. "Intelligent energy management system simulator for PHEVs at municipal parking deck in a smart grid environment." In: 2009 IEEE Power \& Energy Society General Meeting. Calgary, AB, July 26-30, 2009, pp. 1-6. DOI: 10.1109/PES.2009.5275688

[10] Moradijoz, M., Parsa Moghaddam, M., Haghifam, M. R., Alishahi, E. "A multi-objective optimization problem for allocating parking lots in a distribution network." International Journal of Electrical Power \& Energy Systems. 46, pp. 115-122. 2013. DOI: 10.1016/j.ijepes.2012.10.041

[11] Di Giorgio, A., Liberati, F., Canale, S. "Optimal electric vehicles to grid power control for active demand services in distribution grids." In: 2012 20th Mediterranean Conference on Control \& Automation (MED). Barcelona, July 3-6, 2012, pp. 1309-1315. DOI: 10.1109/MED.2012.6265820

[12] Han, S., Han, S., Sezaki, K. "Development of an Optimal Vehicle-toGrid Aggregator for Frequency." IEEE Transactions on Smart Grid. 1(1), pp. 65-72. 2010. DOI: 10.1109/TSG.2010.2045163

[13] Sanchez-Martin, P., Sanchez, G., Morales-Espana, G. "Direct Load Control Decision Model for Aggregated EV Charging Points." IEEE Transactions on Power Systems. 27(3), pp. 1577-1584. 2012. DOI: 10.1109/TPWRS.2011.2180546

[14] Sandels, C., Franke, U., Ingvar, N., Nordstrom, L., Hamren, R. "Vehicle to Grid - Monte Carlo simulations for optimal Aggregator strategies." In: 2010 International Conference on Power System Technology (POWERCON), Hangzhou, Oct. 24-28, 2010. pp. 1-8. DOI: 10.1109/POWERCON.2010.5666607

[15] Kempton, W., Tomić, J. "Vehicle-to-grid power fundamentals: Calculating capacity and net revenue." Journal of Power Sources. 144(1), pp. 268-279. 2005. DOI: 10.1016/j.jpowsour.2004.12.025

[16] Baran, M. E., Wu, F. F. "Network reconfiguration in distribution systems for loss reduction and load balancing." IEEE Transactions on Power Delivery. 4(2), pp. 1401-1407. 1989. DOI: 10.1109/61.25627

[17] Ali, A-F., Abdel-Akher, M., Ziadi, Z., Senjyu, T. "Coordinated charging of plug-in hybrid electric vehicle for voltage profile enhancement of distribution systems." In: 2013 IEEE 10th International Power Electronics and Drive Systems (PEDS), Kitakyushu, April 22-25, 2013, pp. 399-404. DOI: 10.1109/PEDS.2013.6527052

[18] "A Modeling Language for Mathematical Programming." [Online]. Available from: http://www.ampl.com/. [Accessed: 8th June 2016] 